\title{
Regulating the Electron Localization of Metallic Bismuth for Boosting $\mathrm{CO}_{2}$ Electroreduction
}

Cite as

Nano-Micro Lett.

(2022) 14:38

Received: 24 August 2021

Accepted: 11 November 2021

Published online: 18 December 2021

(C) The Author(s) 2021

\author{
Dan $\mathrm{Wu}^{1}$, Renfei Feng ${ }^{2}$, Chenyu Xu ${ }^{3}$, Peng-Fei Sui ${ }^{3}$, Jiujun Zhang ${ }^{4}$, Xian-Zhu Fu ${ }^{1}$, \\ Jing-Li Luo ${ }^{1 凶}$
}

\section{HIGHLIGHTS}

- B atoms modify the local electronic structure of Bi with positive valence sites. B doped Bi boosts highly efficient electroreduction of $\mathrm{CO}_{2}$ to formate.

- B dopant differentiates the proton participations in $\mathrm{CO}_{2} \mathrm{RR}$ and HER processes.

- The dominant mechanistic pathway of B promoted formate generation is unraveled.

ABSTRACT Electrochemical reduction of $\mathrm{CO}_{2}$ to formate is economi-
cally attractive but improving the reaction selectivity and activity remains
challenging. Herein, we introduce boron (B) atoms to modify the local elec-
tronic structure of bismuth with positive valence sites for boosting conver-
sion of $\mathrm{CO}_{2}$ into formate with high activity and selectivity in a wide poten-
tial window. By combining experimental and computational investigations,
our study indicates that $\mathrm{B}$ dopant differentiates the proton participations of
rate-determining steps in $\mathrm{CO}_{2}$ reduction and in the competing hydrogen
evolution. By comparing the experimental observations with the density

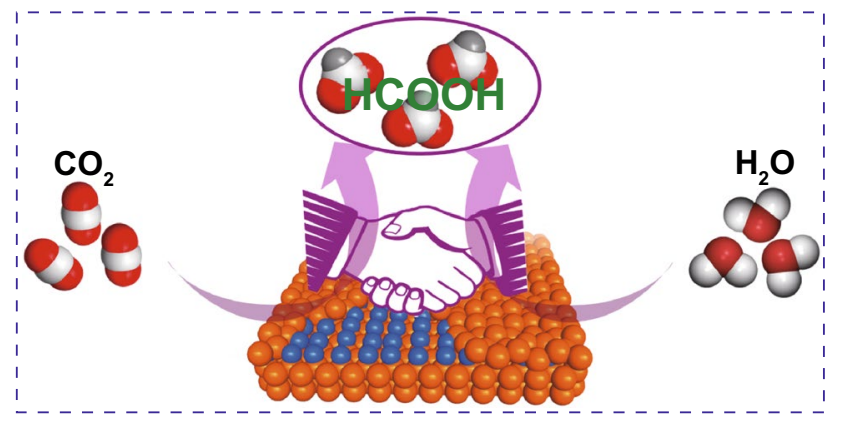
functional theory, the dominant mechanistic pathway of B promoted formate generation and the B concentration modulated effects on the catalytic property of $\mathrm{Bi}$ are unravelled. This comprehensive study offers deep mechanistic insights into the reaction pathway at an atomic and molecular level and provides an effective strategy for the rational design of highly active and selective electrocatalysts for efficient $\mathrm{CO}_{2}$ conversion.

KEYWORDS $\mathrm{CO}_{2}$ reduction; Bismuth; Proton transport; Electron localization; Boron

Xian-Zhu Fu, xz.fu@szu.edu.cn; Jing-Li Luo,jingli.luo@ualberta.ca

1 Shenzhen Key Laboratory of Polymer Science and Technology, Guangdong Research Center for Interfacial Engineering of Functional Materials,

College of Materials Science and Engineering, Shenzhen University, Shenzhen 518060, People's Republic of China

2 Canadian Light Source Inc., Saskatoon, Saskatchewan S7N 0X4, Canada

3 Department of Chemical and Materials Engineering, University of Alberta, Edmonton, AB T6G 1H9, Canada

4 Institute for Sustainable Energy/College of Science, Shanghai University, Shanghai 200444, People's Republic of China 


\section{Introduction}

Electrochemical $\mathrm{CO}_{2}$ reduction reaction $\left(\mathrm{CO}_{2} \mathrm{RR}\right)$ provides a promising approach to the conversion of $\mathrm{CO}_{2}$ waste to highvalue carbon-based fuels and feedstocks when powered by renewable energy sources, thereby presenting an attractive route to energy and environmental sustainability [1-4]. Among the possible $\mathrm{CO}_{2} \mathrm{RR}$ chemical products, formate (or formic acid) is regarded as an attractive liquid product. It can be used as an important raw material in chemical and pharmaceutical industries, or directly as a hydrogen carrier for fuel cell applications [5-7]. Based on the techno-economic analysis, formate is suggested to be one of the most economically profitable products at industrial scale $[8,9]$. Unfortunately, high faradic efficiency can usually be achieved only at the expense of low current density and then would quickly deteriorate with increasing cathodic potentials. As a result, high formate selectivity is limited to a very narrow negative potential window. Therefore, achieving high selectivity combined with high activity in a large potential range is of critical significance to catalyze $\mathrm{CO}_{2}$ to formate in the direction of its commercial viability.

Metal surface has been intensively explored in terms of its electroactivity for formate production via $\mathrm{CO}_{2} \mathrm{RR}$ [10-12]. The electrochemical conversion of $\mathrm{CO}_{2}$ to formate can be generally considered to start with adsorption of $\mathrm{CO}_{2}$ molecules on the metal surface, followed by consecutive proton addition steps to form reaction intermediates and eventually desorbed from the catalyst surface. The key design strategy for a formate-producing metal surface should enable a good control of key intermediates so that the entire reaction pathway has thermodynamically minimum energy barriers. In addition, hydrogen evolution reaction (HER) ineluctably occurs as an additional competing reaction to produce unwanted hydrogen by-products. However, the energetically favorable formate pathway accompanied with hydrogen suppression is difficult to achieve on a clean single metal surface due to the limitation of scaling relationship [13]. Given that the formate generation is governed by the geometric configuration and interfacial chemical bonding of substrate molecules [14-16], controllable modification of the atomic and electronic structure of the metal surface can facilitate $\mathrm{CO}_{2}$ adsorption and activation, thereby enhancing electrocatalytic performance. Fortunately, this can potentially be achieved through several strategies including the implantation of alien atoms into metal structures [17-20].
Heteroatom introduction usually redistributes the electron state of metal catalysts [21, 22], thereby regulating the adsorption of reaction intermediates, which intrinsically affect the electrocatalytic performance in CO2RR.

Bismuth (Bi), as a formate-producing electrocatalyst, has drawn insensitive attention due to its earth abundance, low cost and environmental friendliness. Specially, metal Bi has a unique layered structure with an intralayer $\mathrm{Bi}-\mathrm{Bi}$ bond length of $0.307 \mathrm{~nm}$ and an interlayer $\mathrm{Bi}-\mathrm{Bi}$ bond length of $0.394 \mathrm{~nm}$. This open crystalline structure with large layer distance endows $\mathrm{Bi}$ with heteroatom intercalation that decides its unique properties. In this regard, boron (B) appears to be an ideal non-metal candidate to be incorporated into the $\mathrm{Bi}$ lattice to induce atomic variation of the neighboring metal sites and uneven charge distribution [18, 23], thus open the possibility of further tuning the electrochemical performances to harvest high selectivity in $\mathrm{CO}_{2} \mathrm{RR}$ process.

In this work, $\mathrm{B}$ is intercalated on $\mathrm{Bi}$ to realize a $3 \mathrm{D}$ porous architecture with abundant active sites, achieving high selectivity and activity for $\mathrm{CO}_{2}$ reduction to formate. With the benefits of the unique architecture fabricated, varying the B dopant concentrations can also precisely adjust electronic states of Bi to obtain various oxidative chemical states. Typically, the optimized B modified Bi (denoted as Bi-B2 with B concentration of $2.3 \%$ ) exhibits $>90 \%$ faradic efficiency for formate generation in a large potential window of $494 \mathrm{mV}$. To understand the underlying reaction mechanisms, density functional theory (DFT) calculations are conducted to elucidate the superior formate generation pathways and the suppression of the competing HER in terms of key intermediates during $\mathrm{CO}_{2} \mathrm{RR}$ on $\mathrm{Bi}(012)$ surface with and without $\mathrm{B}$-doping in the subsurface. Besides, the concentration effect of $\mathrm{B}$ dopant on the selectivity and activity of $\mathrm{Bi}$ is also investigated by experiments and DFT simulations. This work provides a profound perception for tailoring the electronic property of materials, and also lays out an effective strategy to develop highly active and selective $\mathrm{CO}_{2} \mathrm{RR}$ electrocatalysts toward desirable products, especially at more negative potentials.

\section{Experimental Section}

\subsection{Preparation of Catalysts}

B-doped Bi samples were prepared by a facile one-step process. Since B solubility in $\mathrm{Bi}$ is low, $\mathrm{Bi}\left(\mathrm{NO}_{3}\right)_{3}$ was added 
into highly concentrated $\mathrm{NaBH}_{4}$ solution instantly in order to alloy the $\mathrm{B}$ with $\mathrm{Bi}$ at as high loading as possible [24]. First, $\mathrm{NaBH}_{4}$ aqueous solution was prepared in an ice bath. Next, $2 \mathrm{~mL}$ ethylene glycol (EG) containing $\mathrm{Bi}\left(\mathrm{NO}_{3}\right)_{3} \cdot 5 \mathrm{H}_{2} \mathrm{O}$ was injected rapidly into the $\mathrm{NaBH}_{4}(5 \mathrm{M}, 2 \mathrm{~mL})$ solution until no bubbles formed in the ice bath. The precipitates obtained were repeatedly washed with ethanol to remove the unreacted precursors and other possible byproducts. Finally, the powder was freezing-dried for use. Different amounts of $\mathrm{Bi}\left(\mathrm{NO}_{3}\right) \cdot 5 \mathrm{H}_{2} \mathrm{O}$ (namely, $600 \mathrm{mg}$ for Bi-B1, $500 \mathrm{mg}$ for $\mathrm{Bi}-\mathrm{B} 2,300 \mathrm{mg}$ for $\mathrm{Bi}-\mathrm{B} 3$ and $100 \mathrm{mg}$ for Bi-B4) were used. The control sample $500 \mathrm{mg}$ for Bi-NH was synthesized following a similar procedure but using an equal amount of hydrazine hydrate instead of $\mathrm{NaBH}_{4}$ as the reducing reagent.

\subsection{Characterizations}

The morphology of the samples was characterized by fieldemission scanning electron microscopy (SEM, SU-70, Hitachi) with accelerating voltages of $5 \mathrm{kV}$ equipped with energy dispersive X-ray spectroscopy (EDS) and high-resolution transmission scanning electron microscopy (HRTEM JEM-F200) with an accelerating voltage of $200 \mathrm{kV}$ equipped with EDS. The phase of catalysts was determined by the SmartLab X-ray diffraction (XRD) with $\mathrm{Cu} \mathrm{K} \alpha$ radiation in the range of $2 \theta$ from $20^{\circ}$ to $80^{\circ}$ with step size of $0.01^{\circ}$ at a scanning speed of $5^{\circ} \mathrm{min}^{-1}$. X-ray photoelectron spectroscopy (XPS) was conducted on a Thermo Scientific ${ }^{\mathrm{TM}}$ K-Alpha ${ }^{\mathrm{TM}^{+}}$spectrometer equipped with a monochromatic $\mathrm{Al} \mathrm{K} \alpha \mathrm{X}$-ray source $(1486.6 \mathrm{eV})$ operating at $100 \mathrm{~W}$. All peaks were calibrated with $\mathrm{C} 1 \mathrm{~s}$ peak binding energy at $284.8 \mathrm{eV}$. Elemental analysis was carried out by inductively coupled plasma optical emission spectroscopy (ICP-OES, ICAP 7000 SERIES Thermo) with three replicates. The nitrogen adsorption/desorption isotherm and the roomtemperature $\mathrm{CO}_{2}$ adsorption isotherm were measured by a Micromeritics 3Flex equipment Tristar II gas adsorption analyzer. The Bi L-edge spectra were collected at the 06ID-1 hard X-ray microprobe beamline from Canadian Light Source.

\subsection{Preparation of Cathode Electrodes}

The catalyst ink was prepared by ultrasonic dispersion of $5 \mathrm{mg}$ of the sample powder with $5 \mu \mathrm{L}$ Nafion solution (5\%) in $950 \mu \mathrm{L}$ ethanol for $1 \mathrm{~h}$. Next, the as-prepared ink was airbrushed driven by $\mathrm{N}_{2}$ gas on the carbon paper with a surface area of $1 \times 1 \mathrm{~cm}^{2}$. The mass loading was about $0.8 \mathrm{mg} \mathrm{cm}^{-2}$.

\subsection{Electrochemical Measurements}

All $\mathrm{CO}_{2}$ reduction experiments were performed in a gastight two-compartment $\mathrm{H}$-cell with an ion exchange membrane (Nafion117) as the separator in the middle of the cell. The anode and cathode sides were filled with $40 \mathrm{~mL}$ of $0.5 \mathrm{M} \mathrm{KHCO}_{3}$, respectively. The Pt foil and $\mathrm{Ag} / \mathrm{AgCl}$ (saturated $\mathrm{KCl}$ ) were used as the reference and counter electrodes, respectively. Firstly, the cathode side was electrochemically reduced using the $\mathrm{CV}$ method, which ranged from -0.8 to $-2.0 \mathrm{~V}$ (versus $\mathrm{Ag} / \mathrm{AgCl}$ ) at a rate of $0.1 \mathrm{~V} \mathrm{~s}^{-1}$ for 10 cycles to completely reduce the possible oxidized species. The gas products from $\mathrm{CO}_{2}$ reduction were analyzed using the gas chromatograph (Fuli 9790Plus) equipped with thermal conductivity and flame ionization detectors on a 3 m-column filled with 5 A molecular sieve column and a packed column (TDX-01, $0.3 \mathrm{~m} \times 4 \mathrm{~mm}$ ) followed by a methanizer using argon as the carrier gas. The liquid samples were collected and analyzed by ion chromatography (Shenghan, CIC-D120) on an SH-AC-3 anion column $\left(250 \times 4.0 \mathrm{~mm}^{2}\right.$ ). The $i R$-corrected potential (versus $\mathrm{Ag} /$ $\mathrm{AgCl}$ ) was converted to $\mathrm{RHE}$ using the following equations: $E_{\mathrm{RHE}}=E_{\mathrm{Ag} / \mathrm{AgCl}}+0.0591 \times \mathrm{pH}+0.197$.

\subsection{Computational Calculations}

Density functional theory (DFT) calculations were performed to calculate electronic energies and to optimize geometries using Vienna ab initio Simulation Package (VASP) $[25,26]$ with the projector augmented wave pseudopotential (PAW) method [27, 28]. The Perdew-BurdewErnzerhof (PBE) coupled with van der Waals (vdW) correction [29] was carried to provide an accurate prediction of chemisorption energies. The cutoff energy for the plane wave basis was set to $400 \mathrm{eV}$. The $\operatorname{Bi}(012)$ surface was modeled using the optimized lattice constants of hexagonal Bi unit cell of $\mathrm{a}=4.569 \AA$ and $\mathrm{c}=11.719 \AA$ and $\mathrm{a}(3 \times 1)$ periodicity in the $\mathrm{x}, \mathrm{y}$ directions and 3 atomic layers in the $\mathrm{z}$ directions, separated by a vacuum layer in the $\mathrm{z}$ direction in the depth of $15 \AA$. This $\mathrm{Bi}(012)$ surface contains $54 \mathrm{Bi}$ 
atoms. Geometry optimizations were performed until the residual force on each atom became less than $0.02 \mathrm{eV} \AA^{-1}$. The electronic energy was considered self-consistent when the energy change was smaller than $10^{-5} \mathrm{eV}$. The gamma point in the Brillouin zone was used for k-point sampling. Free energies for gaseous molecules were treated using the ideal gas approximation at $298.15 \mathrm{~K}$ and $1 \mathrm{bar}$. Using free energies of reaction intermediates, the free energy change in each proton - electron transfer step was calculated utilizing the computational hydrogen electrode (CHE) method, which estimates a chemical potential of protons and electrons from the chemical potential of gaseous $\mathrm{H}_{2}$ and applied potential $\left(\mu\left(\mathrm{H}^{+}+\mathrm{e}^{-}\right)=1 / 2\left[\mu\left(\mathrm{H}_{2}\right)\right]-\mathrm{eU}\right)$. In addition, we also applied the subsurface B concentrations of 1/18 monolayer (ML), 9/18 ML, 18/18 ML, respectively, in the $\mathrm{Bi}(012)$ slab to examine the various concentrations of boron in the B-doped Bi system.

\section{Results and Discussion}

\subsection{Boron Dopant Tuned Morphology and Electronic State of Bi Catalyst}

The rhombohedral $\mathrm{Bi}$ has layered structure with the interlayer distance of $0.394 \mathrm{~nm}$ [30] while B has a smaller atomic radius of $0.086 \mathrm{~nm}$, suggesting that the $B i$ structure can tolerate the incorporation of B atoms. The B-doped Bi was synthesized through a facile wet chemical reduction process using $\mathrm{NaBH}_{4}$ and bismuth nitrate as the reducing agent/B source and metal source, respectively. $\mathrm{Bi}^{3+}$ salt dissolved in EG was poured into highly concentrated $\mathrm{NaBH}_{4}$ solution in order to alloy the $\mathrm{B}$ with $\mathrm{Bi}$ at as high loading as possible. The $\mathrm{BH}_{4}{ }^{-}$ions can reduce the $\mathrm{Bi}$ precursor to Bi crystals. Meanwhile, $\mathrm{BH}_{4}{ }^{-}$ions may decompose on the surface of Bi nanocrystals to produce B atoms [24]. At this point, $\mathrm{B}$ atoms were diffused and successfully inserted into the interstitials of host Bi layered crystal structure [31-33]. For comparison, Bi-H sample was synthesized using hydrazine as the reducing agent to exclude any B doping (Fig. $\mathrm{S} 1)$. The representative $\mathrm{B}$-doped $\mathrm{Bi}$ sample (Bi-B2) is of the rhombohedral crystalline $\mathrm{Bi}$ (PDF 01-085-1331) with a dominant (012) diffraction peak (Fig. S2). Compared to $\mathrm{Bi}-\mathrm{H}$, the (012) peak of $\mathrm{Bi}-\mathrm{B} 2$ shifts to low $2 \theta$, corresponding to an enlarged $\mathrm{Bi}$ interplanar distance with $\mathrm{B}$ incorporation in the interstitials $[34,35]$. Due to the large difference of the atomic radius between $\mathrm{Bi}$ and $\mathrm{B}$ elements, a dramatic variation occurs if $\mathrm{B}$ substitutes the $\mathrm{Bi}$ metal atoms in lattice position, resulting in a relative unstable structure. Therefore, the B atoms are suggested to thermodynamically occupy the interstitials of Bi metal [36, 37]. Noticeably, the widened diffraction peak for B-B2 suggests that the crystallinity is reduced by $\mathrm{B}$ doping $[38,39]$. The scanning electron microscopy (SEM) and transmission electron microscopy (TEM) images show that Bi-B2 catalysts have a porous morphology featuring 3D nanostructure on the scale of 5-10 nm (Fig. 1a, $\mathrm{b}$ and $\mathrm{S} 3$ ). Some of the Bi nanoparticles demonstrate a clear lattice fringe of $0.34 \mathrm{~nm}$ which is assigned to the (012) plane of Bi crystal (insert in Fig. 1b). Besides, B atoms with small atomic diameter are found within the atomic lattice of Bi (Fig. 1c). Notably, the incorporation of Bi also leads to atomic disorder or distortion for a portion of Bi crystals (Figs. 1d and S4). The energy dispersive spectra (EDS) measurement demonstrates that both elemental $\mathrm{Bi}$ and $\mathrm{B}$ are uniformly distributed both on the nano-scale (Fig. 1e) and on the micrometer scale (Fig. S5). In addition, Bi-B2 also possesses decent porous network, which is comprised of macropores existing in voids between the interconnected fragments as well as mesopores with a broad pore size distribution (Fig. 1f). The SEM images and corresponding EDX mappings of other Bi-B samples are shown in Fig. S6. All the obtained B incorporated Bi samples exhibit a similar 3D porous architecture morphology with pure metallic Bi phase (Fig. S7). The significant figure of merit with porous channels can increase the accessibility of the reactive substrate to the active sites with shortened diffusion distance, which is beneficial for the electrolysis on the catalyst surface [40-42].

As shown in Fig. 2a, the X-ray photoelectron spectroscopy (XPS) spectrum of B $1 \mathrm{~s}$ located at the binding energy of 191.6 and $187.9 \mathrm{eV}$ can be assigned to the metal-B bond and surface oxidized B, respectively [31, 37, 43]. Moreover, the relative concentration of meal-B in the XPS profiles increases with $\mathrm{Ar}^{+}$etching time (Fig. S8), suggesting that the $\mathrm{B}$ is incorporated inside the $\mathrm{Bi}-\mathrm{B} 2$ architectures instead of only existed on the surface. Noticeably, due to the sponge-like mesoporous structure assembled with small nanosized $(5-10 \mathrm{~nm})$ nanoparticles, the vulnerable surface oxidized metallic $\mathrm{Bi}$ and $\mathrm{B}$ atoms cannot be totally removed on the $\mathrm{Ar}^{+}$etching mode. The X-ray absorption near-edge spectroscopic (XANES) data at the L-edge were recorded to study the impact of boron incorporation on the Bi oxidation state. The absorption edge position of $\mathrm{Bi}-\mathrm{B} 2$ resides between 

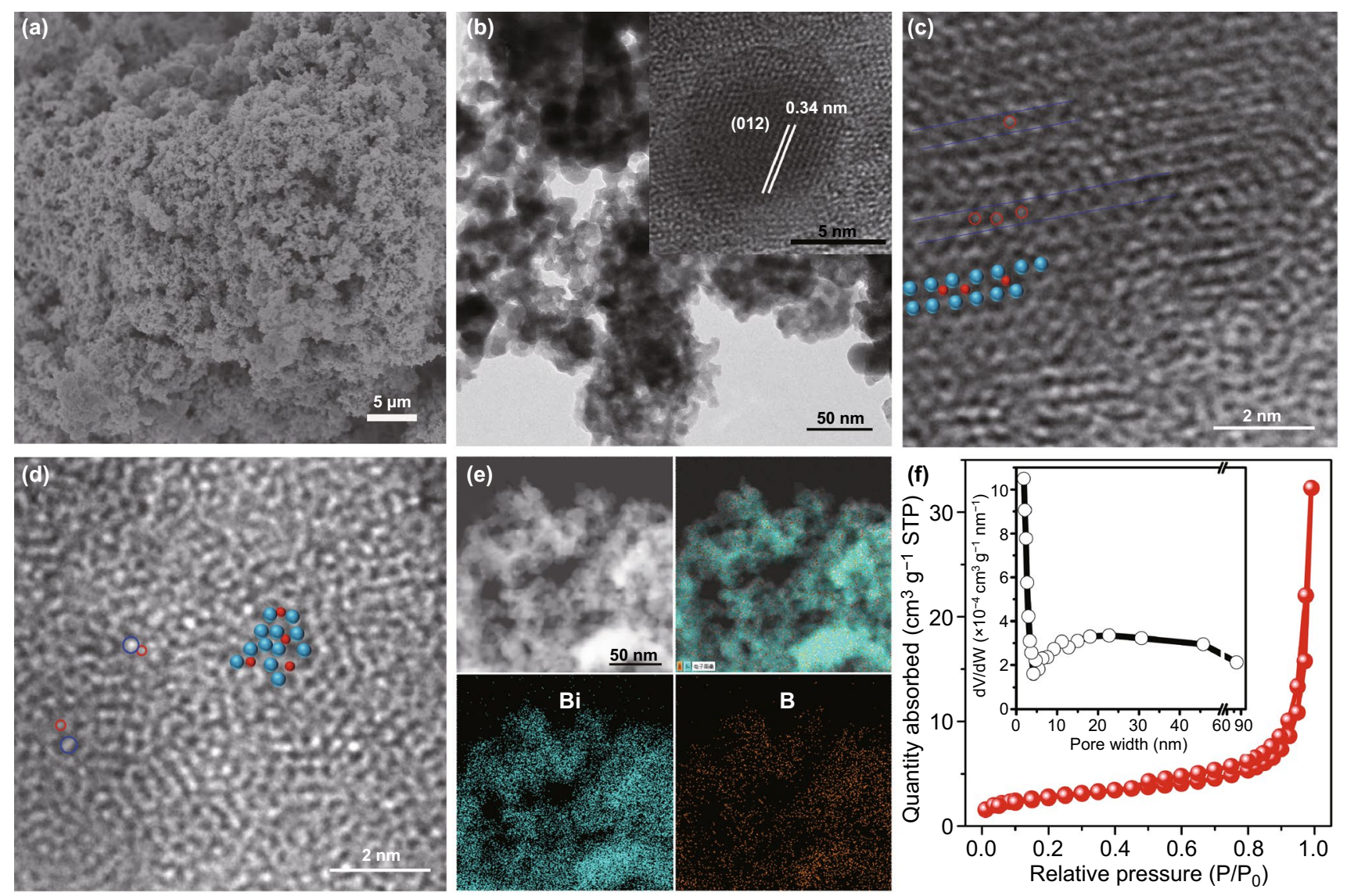

Fig. 1 a SEM b TEM, c, d HRTEM images (the blue and red balls represent the Bi and B atoms, respectively), e HAADF-STEM images and the corresponding STEM-EDS element mappings, $\mathbf{f} \mathrm{N}_{2}$ adsorption-desorption isotherms and the corresponding pore size distribution curve for Bi-B2 catalysts

$\mathrm{Bi}-\mathrm{H}$ and $\mathrm{Bi}_{2} \mathrm{O}_{3}$ (Fig. 2b), suggesting that $\mathrm{B}$ incorporation induces higher oxidation state of $\mathrm{Bi}$ than that of $\mathrm{Bi}-\mathrm{H}$. This is mainly due to the slightly higher electronegativity of $\mathrm{B}$, allowing electron to easily flow from Bi to adjacent $\mathrm{B}$ and leave the surrounding $\mathrm{Bi}$ atoms in an electron-deficient state. To visually compare the oxidation state of $\mathrm{Bi}$ in $\mathrm{Bi}-\mathrm{B}$ samples, the Bi oxidation states as a function of L-edge energy shift were acquired (Fig. S9). The energy shifts in Fig. 2c clearly indicate that the average oxidation states of $\mathrm{Bi}$ in all the $\mathrm{Bi}-\mathrm{B}$ architectures vary between 0 and $+3[44,45]$. The presence of $\mathrm{B}$ in the $\mathrm{Bi}-\mathrm{B}$ samples is also verified by XPS spectra (Fig. S10) and the concentration of B (B/Bi ratio) is quantitatively and qualitatively identified by inductively coupled plasma optical emission spectroscopy (ICP-OES). The atomic ratio of $\mathrm{B}$ to $\mathrm{Bi}$ in $\mathrm{Bi}-\mathrm{B}$ samples increases from $1.9 \%$ to $3.6 \%$ linearly accompanied by more positive shift of the adsorption edge (Fig. 2d), further confirming that B incorporation can tune the oxidation state of $\mathrm{Bi}$ in the $\mathrm{Bi}-\mathrm{B}$ architectures.

\subsection{Electrochemical Performances of B Dopant Tuned Bi Catalysts}

To explore the $\mathrm{B}$ incorporation effect on $\mathrm{CO}_{2} \mathrm{RR}$, the electrochemical $\mathrm{CO}_{2}$ reduction measurements for $\mathrm{Bi}-\mathrm{H}$ and representative $\mathrm{Bi}-\mathrm{B} 2$ catalysts were conducted in a $\mathrm{CO}_{2}$-sarurated $0.5 \mathrm{M} \mathrm{KHCO}_{3}$ electrolyte within an $\mathrm{H}$-cell configuration. The electrochemical activity was firstly examined by linear-sweep-voltammetry (LSV) measurements. As shown in Fig. 3a, the LSV curves have the same shape but larger current density below $-0.6 \mathrm{~V}$ in $\mathrm{CO}_{2}$ atmosphere for Bi-B2, indicating a higher activity of $\mathrm{Bi}-\mathrm{B} 2$ over Bi-H catalysts. Product analysis demonstrates 

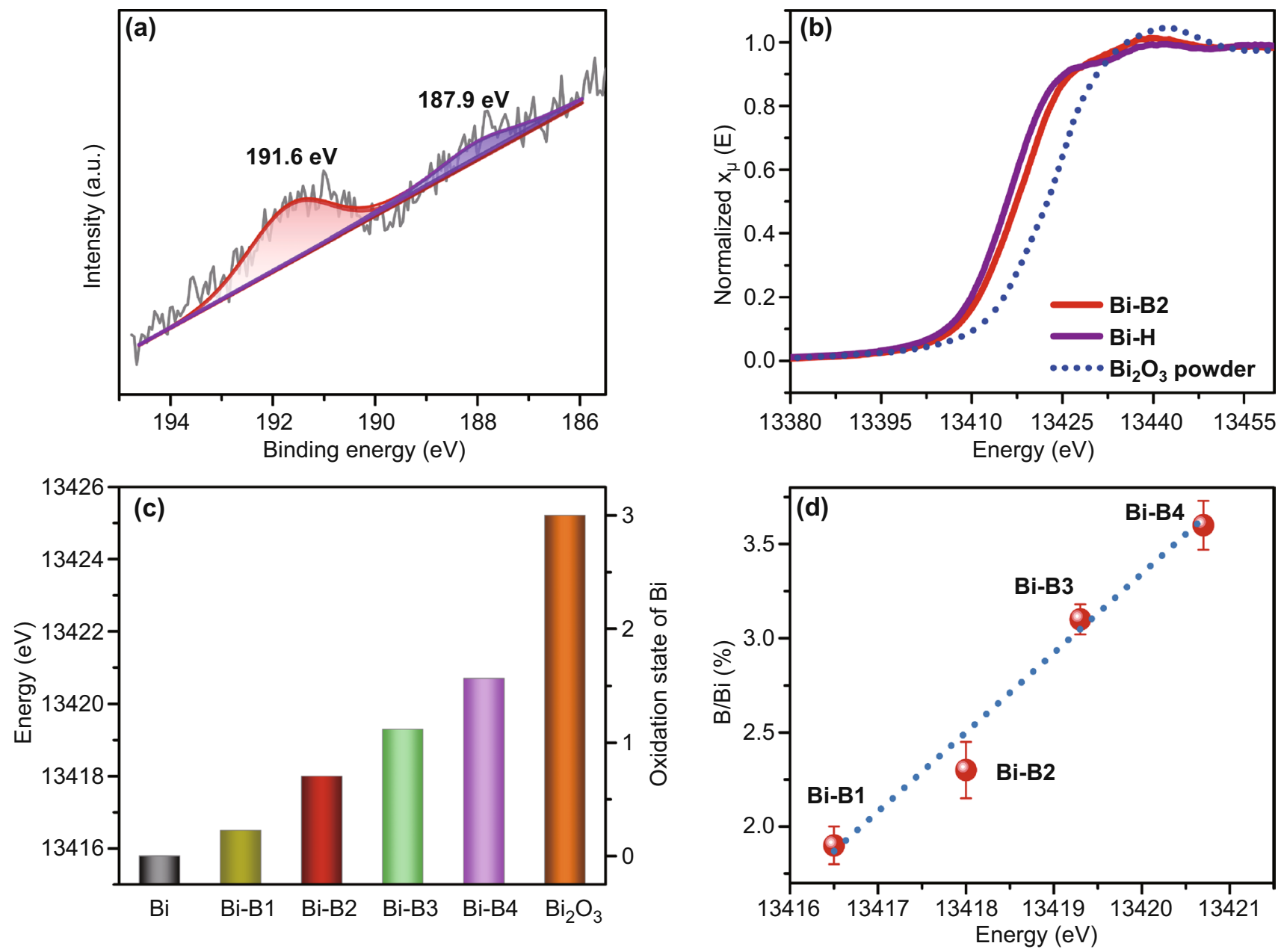

Fig. 2 a High-resolution XPS B 1s spectra of Bi-B2, b Bi L-edge XANES spectra of Bi-B2 and Bi-H samples, $\mathbf{c}$ oxidation state of Bi and $\mathbf{d}$ the relationship between the ratio of $\mathrm{B} / \mathrm{Bi}$ related and the absorption edge position obtained from $\mathrm{Bi}$ L-edge XANES in different samples

that $\mathrm{H}_{2}$ and negligible $\mathrm{CO}$ are the gaseous product and formate is the only liquid product (Figs. $3 \mathrm{~b}$ and S11). For $\mathrm{Bi}-\mathrm{B} 2$, the formate is initially detected at as positive as $-0.57 \mathrm{~V}$, which exhibits smaller overpotential for converting $\mathrm{CO}_{2}$ than that of $\mathrm{Bi}-\mathrm{H}$ with formate initially being measurable at $-0.67 \mathrm{~V}$. After reaching a maximum value of $90.5 \%$ at $-0.76 \mathrm{~V}$, the formate $\mathrm{FE}$ for Bi-H quickly drops to $54.6 \%$ at $-1.18 \mathrm{~V}$ with rapidly increased $\mathrm{H}_{2}$ selectivity. In contrast, the formate FE for Bi-B2 sharply rises to $90.7 \%$ at $-0.72 \mathrm{~V}$ and maintains at $>95.1 \%$ in a large potential window of -0.75 to $-1.22 \mathrm{~V}$. A significantly much wider potential window of $0.494 \mathrm{~V}$ with formate $\mathrm{FE}>90 \%$ and $381 \mathrm{mV}$ with formate $\mathrm{FE}>95 \%$ can be observed from Fig. 3c. To the best of our knowledge, such a wide potential range with high selectivity of formate for Bi-B2 porous architecture outperforms many recently reported state-of-the-art Bi-based electrocatalysts (Table S1). Furthermore, Bi-B2 shows an ultrahigh partial current density of formate up to $56.5 \mathrm{~mA} \mathrm{~cm}^{-2}$ at $-1.22 \mathrm{~V}$, which is more than twice higher than that of $\mathrm{Bi}-\mathrm{H}\left(21.1 \mathrm{~mA} \mathrm{~cm}^{-2}\right.$ ) under the same potential (Fig. 3d). In addition, the double-layer capacitance $\left(\mathrm{C}_{\mathrm{dl}}\right)$ value slightly increases from $3.45 \mathrm{mF} \mathrm{cm}$ co $^{-2} \mathrm{Bi}-\mathrm{H}$ to 3.71 $\mathrm{mF} \mathrm{cm}{ }^{-2}$ of Bi-B2 (Fig. S12). The partial current density of formate was further normalized by $\mathrm{C}_{\mathrm{dl}}$ value as it is positively correlated to the electrochemical active surface area (ECSA) of the catalysts. The $\mathrm{C}_{\mathrm{dl}}$-normalized current density indicates that the slightly increased ECSA is not the predominant reason for the enhanced current density after B incorporation. Remarkably, Bi-B2 also exhibits 
prominently stable electrolysis performance for a longterm test (Fig. 3e). After constantly delivering a current density of about $5 \mathrm{~mA} \mathrm{~cm}^{-2}$ at $-0.75 \mathrm{~V}$ for $20 \mathrm{~h}$, it subsequently keeps a high current density of about $52 \mathrm{~mA} \mathrm{~cm}^{-2}$ at $-1.05 \mathrm{~V}$ for another $10 \mathrm{~h}$. And the corresponding formate FEs stabilize at about $95 \%$ with no obvious deterioration. Moreover, the $\mathrm{Bi}-\mathrm{B} 2$ catalyst also maintains its original morphology after the long-time electrolysis (Fig. $\mathrm{S} 13)$. Furthermore, the atomic ratio of $\mathrm{B} / \mathrm{Bi}$ for $\mathrm{Bi}-\mathrm{B} 2$ is measured as $(2.97 \pm 0.12) \%$ by ICP-OES analysis, which is comparable to that before long-time electrolysis. The existence of $B$ in the sample is confirmed by the high-resolution B $1 \mathrm{~s}$ spectrum with a larger proportion of metalB bond (Fig. S14a). Owing to the higher electronegativity of $\mathrm{B}$ than $\mathrm{Bi}, \mathrm{Bi}$ would transfer electrons to $\mathrm{B}$ in the sample [32, 37]. As a result, more exposed $B$ atoms after electroreduction lead to a positive shift $(0.2 \mathrm{eV})$ of metallic Bi peak (Fig. S14b). Conclusively, the Bi-B2 porous architectures prove to be excellent formate-producing $\mathrm{CO}_{2} \mathrm{RR}$ electrocatalyst with high activity, selectivity, and durability. The reaction kinetics for $\mathrm{CO}_{2} \mathrm{RR}$ is examined by the Tafel plots (Fig. 3f). Bi-B2 demonstrates a smaller Tafel slope of $65 \mathrm{mV} \mathrm{dec}^{-1}$ than that of Bi-H $(106 \mathrm{mV}$ $\mathrm{dec}^{-1}$ ), evidencing its more favorable $\mathrm{CO}_{2} \mathrm{RR}$ kinetics. As revealed by the Nyquist plots (Fig. S15), the smaller semicircle diameter of $\mathrm{Bi}-\mathrm{B} 2$ than that of $\mathrm{Bi}-\mathrm{H}$ implies the much favorable charge transfer kinetics induced by $\mathrm{B}$ incorporation [46, 47]. Notably, the Tafel slope close to $118 \mathrm{mV} \mathrm{dec}^{-1}$ clarifies that the first electron transfer step is the rate-determining step, whereas the value reaching $59 \mathrm{mV} \mathrm{dec}{ }^{-1}$ suggests that the reaction kinetics of $\mathrm{CO}_{2}$ reduction is limited by an electron coupling proton $\left(\mathrm{H}^{+}\right)$ transfer step preceded by an initial electron transfer process $[48,49]$. The Tafel slopes distinction illustrates that the conversion of $\mathrm{CO}_{2}$ to formate is kinetically altered by $\mathrm{B}$ incorporation. Given that $\mathrm{HCO}_{3}{ }^{-}$serves as the $\mathrm{H}^{+}$donor in $\mathrm{CO}_{2}$ reduction reactions on a thermodynamic basis with the $\mathrm{pKa}$ value of $\mathrm{HCO}_{3}{ }^{-}(\mathrm{pKa}=10.3)$ being much lower than that of $\mathrm{H}_{2} \mathrm{O}(\mathrm{pKa}=14)$, the hydrogenation effect of $\mathrm{HCO}_{3}{ }^{-}$ranging from 0.1 to $0.5 \mathrm{M}$ is performed [50]. Bi-B2 exhibits a quasi-first-order (0.92) dependence on $\mathrm{HCO}_{3}{ }^{-}$concentration, manifesting that reaction electrokinetic $\mathrm{CO}_{2}$ reduction over $\mathrm{Bi}-\mathrm{B} 2$ is mainly controlled by the $\mathrm{H}^{+}$transfer step. This $\mathrm{H}^{+}$manipulation process can be attributed to the presence of oxidative state of $\mathrm{Bi}$, which is established by the previous observation for the ratedetermining route switching [51].

To investigate high-current performance for the practical application of $\mathrm{CO}_{2} \mathrm{RR}$, we incorporated $\mathrm{Bi}-\mathrm{B} 2$ catalysts within the flow cell configuration tested in $1 \mathrm{M} \mathrm{KOH}$. As revealed in Fig. S16, the formate selectivity remains above $80 \%$ at a wide range and the corresponding partial current density increases from 1.1 to $521.4 \mathrm{~mA} \mathrm{~cm}^{-2}$ as the applied potential changes from -0.2 to $-1.1 \mathrm{~V}$. A large current density at $222 \mathrm{~mA} \mathrm{~cm}^{-2}$ with stable formate selectivity of over $95 \%$ is sustained at $-0.8 \mathrm{~V}$, indicating an excellent catalytic performance that is suitable for commercial applications.

\subsection{Enhanced Reaction Mechanism of B Dopant Tuned Bi Catalysts}

To further illustrate the B incorporation enhanced reaction mechanism for formate generation and the origin of high formate selectivity in a wide negative potential range, DFT study was undertaken based on the (012) plane for pristine $\mathrm{Bi}$ and $\mathrm{B}$-doped $\mathrm{Bi}(\mathrm{Bi}-\mathrm{B})$. From the geometrical structure optimization, B with small atomic radius prefers to diffuse into the subsurface of a $\mathrm{Bi}(012)$ slab rather than remains on the surface, which is consistent with aforementioned XPS and HRTEM analyses. The formation of $\mathrm{HCOOH}$ from $\mathrm{CO}_{2}$ involves two proton-coupled electron transfer steps. The $\mathrm{CO}_{2}$ absorbed on the catalyst surface $\left({ }^{*} \mathrm{CO}_{2}\right)$ firstly receives one electron from the electrode and couples one $\mathrm{H}^{+}$from the electrolyte to form formate $(* \mathrm{HCOO})$ or carboxyl $(* \mathrm{COOH})$ intermediate. Then, the intermediates continue to combine an electron and a $\mathrm{H}^{+}$to generate adsorbed $\mathrm{HCOOH}$ $\left({ }^{*} \mathrm{HCOOH}\right)$ and finally desorb from the catalyst surface to form $\mathrm{HCOOH}$ in the electrolyte. As the energy profile in Fig. S17 shown, the lower energy barriers $(\Delta \mathrm{G})$ indicate that the energetically favorable reaction pathway from $\mathrm{CO}_{2}$ to the formate generation is through the formation of $* \mathrm{OCHO}$ intermediate for both pristine $\mathrm{Bi}$ and $\mathrm{Bi}-\mathrm{B}$. Besides, in situ Raman spectroscopy studies in Fig. S18 clearly evidence the $\mathrm{C}-\mathrm{O}$ symmetric and asymmetric stretching vibrations of *OCHO $\left(1300 \sim 1600 \mathrm{~cm}^{-1}\right)$ and a new band at $\sim 2900 \mathrm{~cm}^{-1}$ as a marker of $* \mathrm{HCOO}[52-54]$, further confirming that the conversion of $\mathrm{CO}_{2}$ to formate on $\mathrm{B}$ doped $\mathrm{Bi}$ is through *OCHO intermediates. 

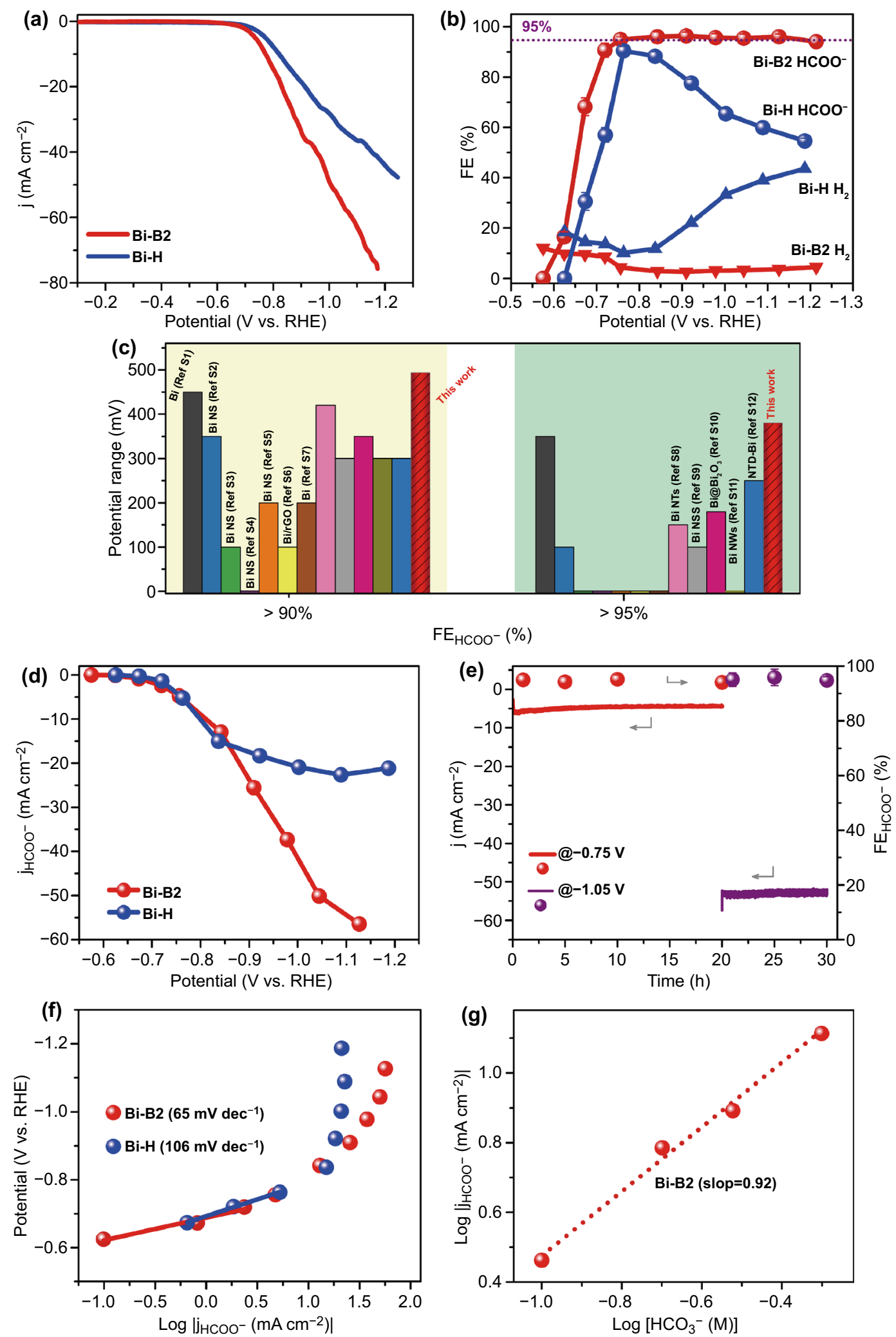

Fig. 3 a LSV curves in $\mathrm{CO}_{2}$ saturated solution and $\mathbf{b}$ FEs of formate and $\mathrm{H}_{2}$ for $\mathrm{Bi}-\mathrm{B} 2$ and $\mathrm{Bi}-\mathrm{H}$, $\mathbf{c}$ comparison of the-state-of-the-art $\mathrm{Bi}$-based electrocatalysts with high formate FEs, $\mathbf{d}$ formate partial current density for $\mathrm{Bi}-\mathrm{B} 2$ and $\mathrm{Bi}-\mathrm{H}$, e long-term stability test at $-0.75 \mathrm{~V}$ for $20 \mathrm{~h}$ and further at $-1.05 \mathrm{~V}$ for $10 \mathrm{~h}$ for $\mathrm{Bi}-\mathrm{B} 2, \mathbf{f}$ Tafel slopes for Bi-B2 and $\mathrm{Bi}-\mathrm{H}$ and $\mathbf{g}$ bicarbonate order dependence data at $-0.84 \mathrm{~V}$ for Bi-B2 
The free energy diagram of the *OCHO intermediated pathways in terms of multi-step reaction process for the formate generation is plotted in light of the above comparison. At the external potential of $0 \mathrm{~V}$, on the pristine $\mathrm{Bi}(012)$ surface, the activation of $\mathrm{CO}_{2}$ to form ${ }^{*} \mathrm{CO}_{2}$ and the subsequent hydrogenation processes of $* \mathrm{CO}_{2}$ to $* \mathrm{OCHO}$ and $* \mathrm{OCHO}$ to $* \mathrm{HCOOH}$ are uphill pathways with large endothermic energy barriers, as shown in Fig. $4 \mathrm{a}$. In the case of $\mathrm{Bi}-\mathrm{B}$, the $\Delta \mathrm{G}$ required to form these key intermediates is much lower compared to those of $\mathrm{Bi}$, indicating a promoted electrocatalytic activity from $\mathrm{CO}_{2}$ to formate caused by B incorporation. More specifically, the energy barrier to form $* \mathrm{CO}_{2}$ declines markedly from $0.55 \mathrm{eV}$ for $\mathrm{Bi}$ to $0.29 \mathrm{eV}$, implying that $\mathrm{CO}_{2}$ molecule is more effectively adsorbed on the $\mathrm{Bi}-\mathrm{B}$ surface. This agrees well with the fact that the adsorption capacity of Bi-B2 is larger than that of $\mathrm{Bi}-\mathrm{H}$ from the results of experimental volumetric $\mathrm{CO}_{2}$ adsorption isotherms (Fig. S19). Then, the $* \mathrm{CO}_{2}$ is exothermically and spontaneously hydrogenated to $* \mathrm{OCHO}$ with $\Delta \mathrm{G}=-0.13 \mathrm{eV}$, and $* \mathrm{OCHO}$ is further hydrogenated to $* \mathrm{HCOOH}$ with an uphill pathway of $\Delta \mathrm{G}=0.51 \mathrm{eV}$ for Bi-B. In conjunction with the result of kinetic Tafel analysis, the second $\mathrm{H}^{+}$-assisted electron transfer process to $* \mathrm{HCOOH}$ is considered as the ratedetermining step (RDS). Notably, this energy barrier for $* \mathrm{OCHO}$ to $* \mathrm{HCOOH}$ is diminished when $\mathrm{U}=-0.51 \mathrm{~V}$ is applied (Fig. 4b). Even though with the energy barrier close to the thermodynamic minimum, Bi still needs to overcome endothermic free energies with $0.04 \mathrm{eV}$ for $* \mathrm{CO}_{2}$ and $0.01 \mathrm{eV}$ for $* \mathrm{OCHO}$ to finally obtain $\mathrm{HCOOH}$, demonstrating the difficulty for formate generation at this potential. This is in good agreement with the experimental results that more positive onset potential is needed for $\mathrm{Bi}-\mathrm{B}$. Furthermore, the thermodynamic limiting potential difference between $\mathrm{CO}_{2} \mathrm{RR}$ and HER $\left(\mathrm{U}_{\mathrm{L}}\left(\mathrm{CO}_{2}\right)-\mathrm{U}_{\mathrm{L}}\left(\mathrm{H}_{2}\right)\right)$ is a descriptor for $\mathrm{CO}_{2} \mathrm{RR}$ selectivity $[55,56]$. As shown in Fig. $4 c$, Bi-B has more positive $\mathrm{U}_{\mathrm{L}}\left(\mathrm{CO}_{2}\right)-\mathrm{U}_{\mathrm{L}}\left(\mathrm{H}_{2}\right)$ value $(-0.19 \mathrm{eV})$ than pristine $\mathrm{Bi}(-0.31 \mathrm{eV})$, highlighting the advantageous effects of B intercalation on the energetics of formate generation, which is in high consistence with the superior formate selectivity of $\mathrm{B}$-doped $\mathrm{Bi}$, observed from the experimental results.

Given that B doped Bi architectures demonstrate high formate selectivity ( $\mathrm{FE}>95.1 \%$ ) in a wide potential range $(-0.75 \sim-1.22 \mathrm{~V})$, we sought to elaborate the potential dependent mechanistic insights. As revealed by Fig. S20, the free-energy pathway from $\mathrm{CO}_{2}$ to $\mathrm{HCOOH}$ becomes a thermodynamical downhill with the potential of more negative than $-0.6 \mathrm{~V}$ applied on $\mathrm{Bi}$ and $\mathrm{Bi}-\mathrm{B}$ surfaces. In majority of the cases, the insufficient supply of active $\mathrm{CO}_{2}$ on the catalyst surface accounts for the rapid decrease in selectivity toward target reduction product with increasing cathodic potential [57]. As seen from Fig. 4d, the more negative free energies of $* \mathrm{CO}_{2}$ for $\mathrm{Bi}-\mathrm{B}$ than that for $\mathrm{Bi}$ at the same potential suggest that $\mathrm{CO}_{2}$ molecules are energetically favorable to bind onto the Bi surface with $\mathrm{B}$ incorporation. Furthermore, the smaller energy barrier changes from ${ }^{*} \mathrm{HCOOH}$ to $\mathrm{HCOOH}$ for $\mathrm{Bi}-\mathrm{B}$ (Fig. 4e) imply that the $* \mathrm{HCOOH}$ can be exothermically easier desorbed from the Bi-B surface to form stable formate liquid product in the electrolyte. Synergically, Bi-B exhibits superior formate selectivity in comparison with $\mathrm{Bi}$ at more negative potentials. From the perspective of $* \mathrm{OCHO}$ and $* \mathrm{HCOOH}$ involvement, it is noteworthy that $\mathrm{H}^{+}$indispensably participates in the hydrogenation process for the conversion of $\mathrm{CO}_{2}$ to formate. We have further computationally calculated the energy diagram in terms of the key *H intermediate (Fig. 4f). Interestingly, the free energy of ${ }^{*} \mathrm{H}$ is $0.48 \mathrm{eV}$ on $\mathrm{Bi}-\mathrm{B}$, significantly lower than on pure $\mathrm{Bi}(0.82 \mathrm{eV})$, indicating a higher water dissociation activity on the B modulated surface [58]. At higher cathodic potentials in $\mathrm{CO}_{2} \mathrm{RR}$, the $\mathrm{H}^{+}$is considered to be supplied by $\mathrm{H}_{2} \mathrm{O}$ dissociation [59-61]. When the binding energy of $* \mathrm{H}$ intermediate is too strong, the $* \mathrm{H}$ will occupy the active sites on the catalyst surface. However, if the $* \mathrm{H}$ is bonded too weakly, it is hard for $* \mathrm{H}$ to absorb and to be activated. For instance, with the applied cathodic potential of $-1.0 \mathrm{~V}, \mathrm{Bi}-\mathrm{B}$ has a larger negative $\Delta \mathrm{G}$ of $-0.52 \mathrm{eV}$ than $\mathrm{Bi}(-0.18 \mathrm{eV})$, indicating that it is thermodynamically easier for water dissociation on Bi-B surface to provide $\mathrm{H}^{+}$. This sufficient feed of $\mathrm{H}^{+}$ensures the hydrogenation process from $* \mathrm{CO}_{2}$ to $* \mathrm{HCOOH}$ to proceed in a timely manner on Bi-B surface. Unquestionably, ${ }^{*} \mathrm{H}$ intermediates can also form $\mathrm{H}_{2}$ from simultaneous HER besides $\mathrm{CO}_{2} \mathrm{RR}$. However, the free energies of $\mathrm{CO}_{2}$ activation to form ${ }^{*} \mathrm{CO}_{2}$ and the subsequent two hydrogenation steps are much more negative than that of *H (Fig. S21) in the testing potential range, suggesting that the generation of $\mathrm{HCOOH}$ via $\mathrm{CO}_{2} \mathrm{RR}$ is energetically more preferable than via the undesirable HER. 

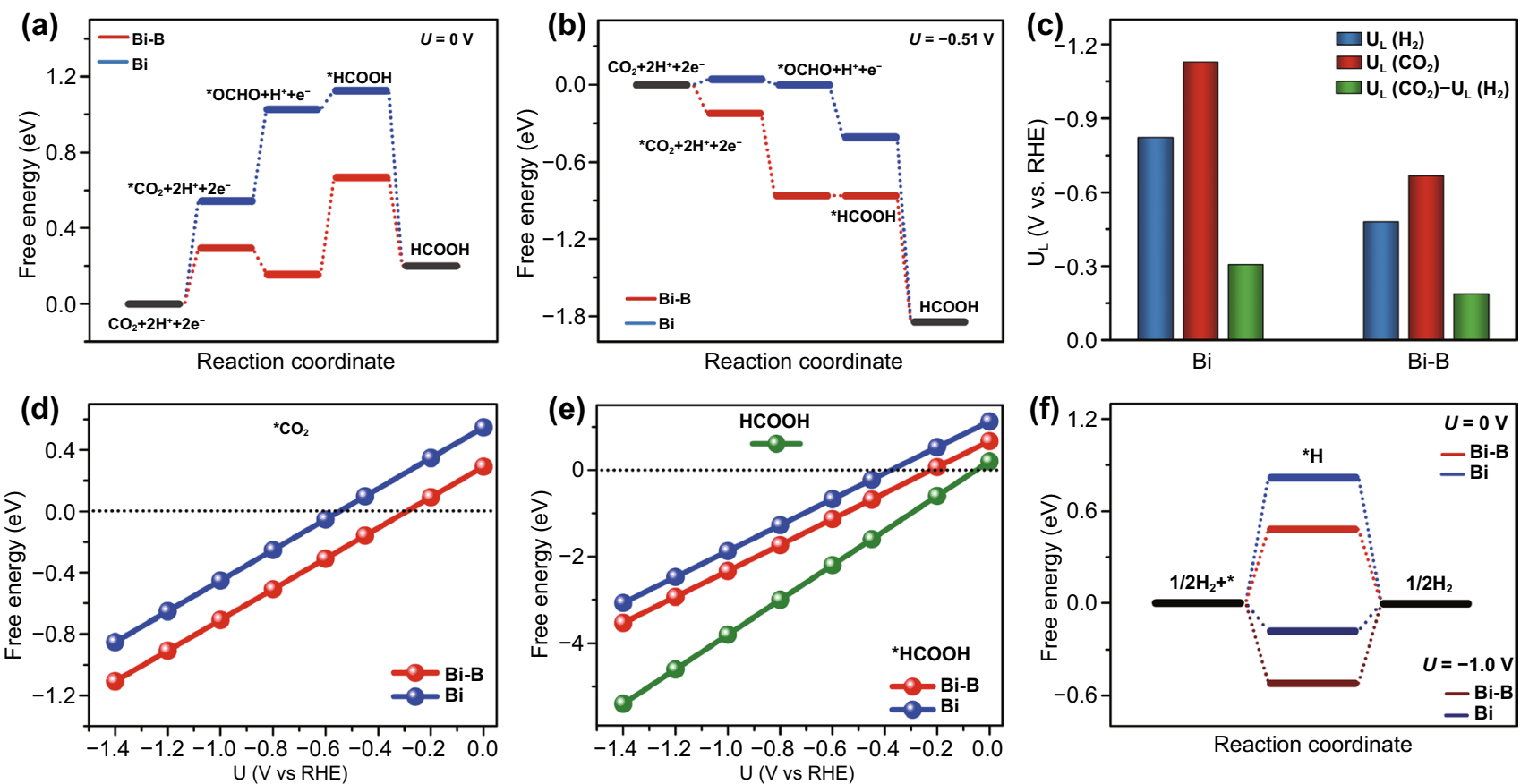

Fig. 4 Mechanistic free-energy diagrams at external potential U (versus reversible hydrogen electrode (RHE) at pH 0, $298 \mathrm{~K}$, and 1 atm) of a $0 \mathrm{~V}$ and $\mathbf{b}-0.51 \mathrm{~V}$, c difference in limiting potentials for $\mathrm{CO}_{2}$ reduction and $\mathrm{H}_{2}$ evolution, free energies of $\mathbf{d} * \mathrm{CO}_{2}, \mathbf{e} * \mathrm{HCOOH}$ and $\mathbf{f} * \mathrm{H}$ at different $\mathrm{U}$ on pristine $\mathrm{Bi}(012)$ and $\mathrm{Bi}-\mathrm{B}(012)$ surfaces

\subsection{Effects of B Dopant Concentration on the Electrochemical Performance of Bi Catalysts}

We also sought to verify whether the B dopant concentration is correlated to the formate selectivity and activity of Bi architecture. As depicted in Fig. 5a, all the B modulated $\mathrm{Bi}$ porous architectures show the high formate selectivity. Nevertheless, the FE of formate Bi-B4 with high $\mathrm{B}$ concentration (3.6\%) gradually decreases when the potential varies from -0.7 to $-1.2 \mathrm{~V}$. Besides, the partial current densities for formate generation on Bi-B1 (B 1.9\%) and $\mathrm{Bi}-\mathrm{B} 4$ are also lower compared to the representative Bi-B2 with B of $2.3 \%$ (Fig. 5b). Apparently, Bi porous architectures with B dopant contents of either too low or too high both fall short in achieving high selectivity and activity for formate generation. We initially investigate $\mathrm{B}$ substitution at the Bi site or occupancy at an interstitial site in layered Bi lattices with 1/18 monolayer (ML) configuration. On the basis of Fig. S22, the free energy of $\mathrm{CO}_{2}$ adsorption, first and second hydrogenation, and $* \mathrm{HCOOH}$ desorption for interstitial $\mathrm{B}$ doped $\mathrm{Bi}$ is lower than that for substitutional $\mathrm{B}$ doped $\mathrm{Bi}$, respectively. This result indicates that the interstitial $\mathrm{B}$ doping is favored over substitutional $\mathrm{B}$ doping in $\mathrm{Bi}$ crystals for $\mathrm{CO}_{2}$-to- $\mathrm{HCOOH}$ conversion. In this study, we have examined the effect of $\mathrm{B}$ concentration on the B-doped Bi system with subsurface B concentrations of 1/18 monolayer (ML), 9/18 ML and 18/18 ML to simulate the situations of low, suitable, and high concentrations of B dopant, respectively. As shown in Fig. 5c, the binding energies of the key $* \mathrm{CO}_{2},{ }^{*} \mathrm{OCHO}$ and $* \mathrm{HCOOH}$ intermediates are more positive in the case of 1/18 ML and 18/18 ML configurations than those in the 9/18 ML configuration at $\mathrm{U}=-1.0 \mathrm{~V}$, inferring a comparably sluggish process to catalyze $\mathrm{CO}_{2}$ to formate on $\mathrm{Bi}$ with either too low or too many B incorporation. Similar free energy profiles are also observed without external potential applied (Fig. S23). Simultaneously, the exothermal free energies of ${ }^{*} \mathrm{H}$ in the 1/18 ML and 9/18 ML configurations are much smaller than those of C-containing intermediates, which guarantees that the formate generation via $\mathrm{CO}_{2} \mathrm{RR}$ is a more favorably achievable process than $\mathrm{H}_{2}$ production via competing HER. However, the 

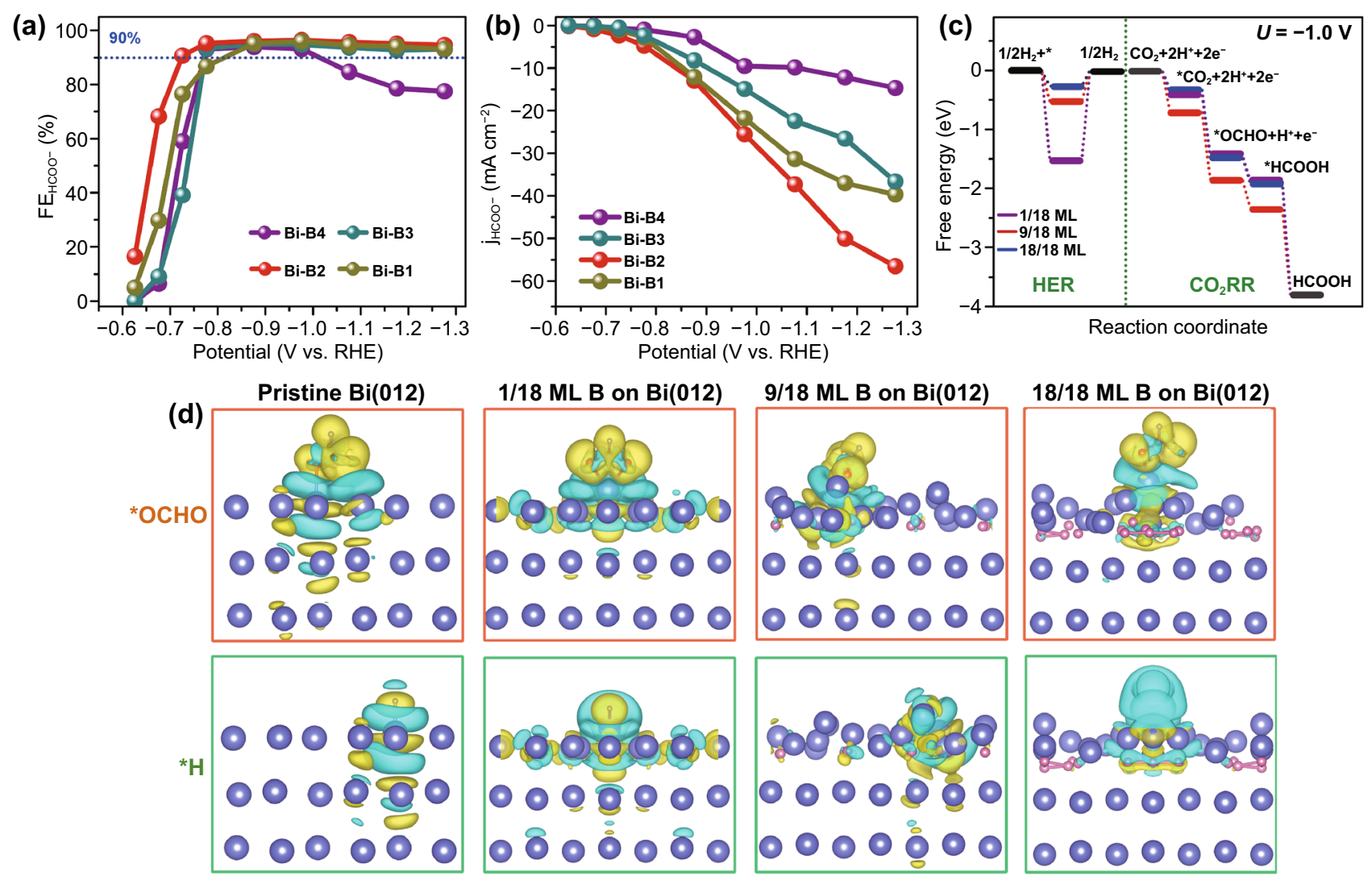

(e)
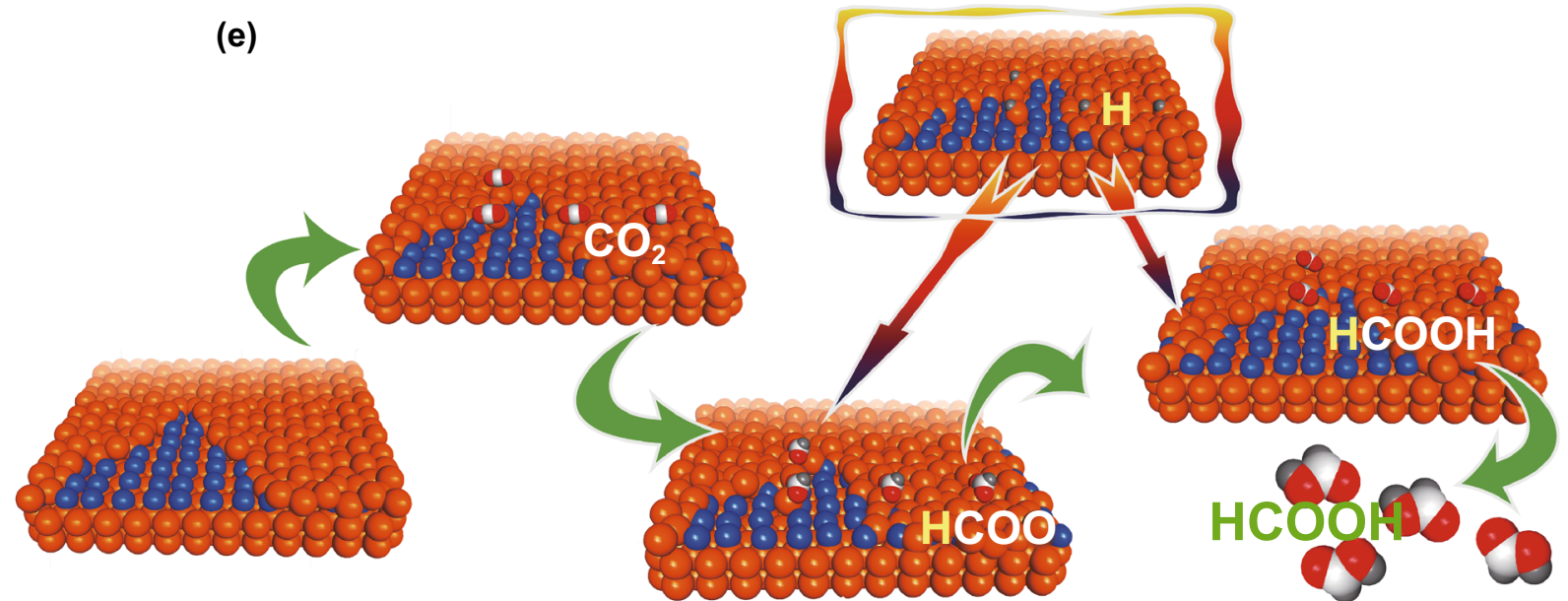

Fig. 5 a FE and b partial current density for formate generation for Bi-B samples, $\mathbf{c}$ free energy diagrams of Bi with different B concentrations at $\mathrm{U}=-1.0 \mathrm{~V}$ and $\mathbf{d}$ side view of differential charge densities of $* \mathrm{OCHO}$ and $* \mathrm{H}$ adsorbed on different surfaces, regions of yellow and cyan denote electron accumulation and depletion, respectively. Blue, pink, brown, red, and pale balls represent $\mathrm{Bi}, \mathrm{B}, \mathrm{C}, \mathrm{O}$, and $\mathrm{H}$ atoms, respectively (The value of isosurface is $0.0005 \mathrm{e}^{-3}$ ). e Schematic illustration for the $\mathrm{H}^{+}$promoted hydronation process of $\mathrm{CO}_{2}$ to formate on $\mathrm{Bi}$ surface with B dopant

more positive $* \mathrm{H}$ free energy in the $1 / 18 \mathrm{ML}$ configuration demonstrates that $\mathrm{Bi}$ with low concentration of $\mathrm{B}$ suffers from a difficult supply of $\mathrm{H}^{+}$, thereby affecting the two hydrogenation steps of $* \mathrm{CO}_{2}$. Although the free energy of $* \mathrm{H}$ in the $18 / 18 \mathrm{ML}$ configuration is more negative to provide sufficient $\mathrm{H}^{+}$in $* \mathrm{CO}_{2}$ hydrogenations, it 
also favors for the competing $\mathrm{H}_{2}$ generation. Moreover, through geometrical optimization, it is found that B-doped Bi surface with the 18/18 ML concentration of B brings about the disordered $\mathrm{Bi}$ atomic structure and aggregation of B atoms (Fig. S24). In addition, Fig. S25 exhibits that the charge transfer ability is weaken when increasing $\mathrm{B}$ to too high concentration within $\mathrm{Bi}$, which is probably attributed to the lower conductivity induced by the presence of too many B dopants. Consequently, the theoretical results provide solid evidence that $\mathrm{Bi}$ with optimized $\mathrm{B}$ concentration can achieve the best activity and selectivity for formate formation in $\mathrm{CO}_{2} \mathrm{RR}$ process.

The differential charge densities of $* \mathrm{OCHO}$ and $* \mathrm{H}$ for subsurface Bi sites without $B$ and with different contents of B were also calculated and shown in Figs. 5d and S26. Compared to the pristine surface, there is evident redistribution of charge density on the $\mathrm{B}$ doped $\mathrm{Bi}$ surface. The electron depletion is observed on the Bi sites while the neighboring $\mathrm{B}$ atoms are surrounded by electron accumulation region, indicating a more positive charged $\mathrm{Bi}$ in Bi-B cases. These positively charged Bi sites could serve as an anchor for $\mathrm{CO}_{2}$ activation and stabilization. Noticeably, more surface Bi sites are affected and positively charged with increasing B dopants, signifying that more reactive sites participate in the reduction of $\mathrm{CO}_{2}$ to formate. With respect to the $\mathrm{Bi}$ sites, the strong charge interaction between $\mathrm{OCHO}$ and $\mathrm{H}$ atom was also partitioned by electron accumulation and depletion region. In the 18/18 ML configuration, obvious charge redistribution is observed among B agglomerations, which severely hinders the electron mobility in the catalyst and reduce the charge transfer rate at the interface [62]. All the above analyses provide solid evidences to elaborate the outstanding electrocatalytic performance of Bi modulated by $\mathrm{B}$ surface engineering with optimized B content for valueadded formate generation.

Based on the above theoretical calculation and experiment results, the mechanism of $\mathrm{CO}_{2} \mathrm{RR}$ on $\mathrm{Bi}-\mathrm{B}$ is proposed (Fig. 5e): the subsurface B dopant with optimized concentration on $\mathrm{Bi}$ surface is proposed to serve as the promoter in $\mathrm{CO}_{2}$ activation and the subsequent protonation of carboncontaining species to transfer $\mathrm{CO}_{2}$ to formate. The $\mathrm{B}$ intercalation induced positively charged $\mathrm{Bi}$ sites favor for the Lewis acid $\mathrm{CO}_{2}$ anchoring. With the advantage of porous structure, the $\mathrm{CO}_{2}$ molecules are preferably absorbed on the $\mathrm{B}$ modified Bi surface. The $\mathrm{B}$ introduction also reduces the thermodynamical energy barriers of C-containing intermediates from $\mathrm{CO}_{2}$ to formate. At the same time, the surfaceadsorbed $\mathrm{H}^{*}$ can be easily derived from the near-surface $\mathrm{HCO}_{3}{ }^{-}$anions attracted by the positive Bi sites at kinetically controlled low negative potentials, and also from $\mathrm{H}_{2} \mathrm{O}$ molecules with low energy barriers at high negative potentials. The readily accessible supply of $* \mathrm{H}$ accelerates the protonation of $* \mathrm{CO}_{2}$ to form $* \mathrm{OCHO}$ and $* \mathrm{HCOO}$. As a result, the optimized content of $\mathrm{B}$ boosts electrochemical $\mathrm{CO}_{2}$ reduction to formate on Bi sites with high selectivity and activity over wide potential range.

\section{Conclusions}

In summary, a facile method is developed to prepare B modulated $\mathrm{Bi}$ architecture with $3 \mathrm{D}$ porous feature. The electroreduction of $\mathrm{CO}_{2}$ to formate and its link to $\mathrm{Bi}$ catalysts with different B concentrations are theoretically and experimentally studied. The finite elemental analyses including XPS and XANES demonstrate that B dopant leads to positively charged Bi sites. The optimized Bi-B2 sample exhibits a significantly wide potential window of $494 \mathrm{mV}$ with formate FE $>90 \%$. Besides, Bi-B2 shows an ultrahigh partial current density of $56.5 \mathrm{~mA} \mathrm{~cm}^{-2}$ with $\mathrm{FE}$ of $95.1 \%$ at $-1.22 \mathrm{~V}$ for formate generation. DFT calculation reveals that the subsurface intercalated $\mathrm{B}$ reduces the energy barriers of $\mathrm{CO}_{2}$ adsorption to form $* \mathrm{CO}_{2}$, hydrogenation to form $* \mathrm{OCHO}$ and $* \mathrm{HCOOH}$, and desorption of $\mathrm{HCOOH}$ from the Bi surface. Furthermore, the absorbed ${ }^{*} \mathrm{H}$ species are confirmed to be responsible for the favorable protonation of $* \mathrm{CO}_{2}$ to $* \mathrm{OCHO}$ and subsequent $* \mathrm{HCOOH}$. With kinetic and thermodynamic preference for $\mathrm{CO}_{2}$ transformation and HER suppression, formate is generated with high selectivity in a wide potential range on B intercalated Bi porous architecture with optimized concentration. In addition, a comprehensive mechanistic study also verifies the relationships between the concentration of $\mathrm{B}$ dopant and $\mathrm{CO}_{2} \mathrm{RR}$ performance of $\mathrm{Bi}$ catalysts. This work opens up more possibilities for rational design of highly efficient $\mathrm{CO}_{2} \mathrm{RR}$ electrocatalysts using earth abundant, cost effective and environmentally friendly materials.

Acknowledgements This work was supported by the Shenzhen Science and Technology Program (KQTD20190929173914967). The authors would like to acknowledge the technical support provided by Instrumental Analysis Center of Shenzhen University 
(Xili Campus) and thank Shiyanjia Lab (www.shiyanjia.com) for the ICP-MS experiments.

Funding Open access funding provided by Shanghai Jiao Tong University.

Open Access This article is licensed under a Creative Commons Attribution 4.0 International License, which permits use, sharing, adaptation, distribution and reproduction in any medium or format, as long as you give appropriate credit to the original author(s) and the source, provide a link to the Creative Commons licence, and indicate if changes were made. The images or other third party material in this article are included in the article's Creative Commons licence, unless indicated otherwise in a credit line to the material. If material is not included in the article's Creative Commons licence and your intended use is not permitted by statutory regulation or exceeds the permitted use, you will need to obtain permission directly from the copyright holder. To view a copy of this licence, visit http://creativecommons.org/licenses/by/4.0/.

Supplementary Information The online version contains supplementary material available at https://doi.org/10.1007/ s40820-021-00772-7.

\section{References}

1. W.H. Ren, C. Zhao, Paths towards enhanced electrochemical $\mathrm{CO}_{2}$ reduction. Natl. Sci. Rev. 7(1), 7-9 (2020). https://doi. org/10.1093/nsr/nwz121

2. H.L. Liu, Y.T. Zhu, J.M. Ma, Z.C. Zhang, W.P. Hu, Recent advances in atomic-level engineering of nanostructured catalysts for electrochemical $\mathrm{CO}_{2}$ reduction. Adv. Funct. Mater. 30(17), 1910534 (2020). https://doi.org/10.1002/adfm.20191 0534

3. F. Franco, C. Rettenmaier, H.S. Jeon, B. Roldan Cuenya, Transition metal-based catalysts for the electrochemical $\mathrm{CO}_{2}$ reduction: From atoms and molecules to nanostructured materials. Chem. Soc. Rev. 49(19), 6884-6946 (2020). Doi: https://doi. org/10.1039/d0cs00835d

4. S. Lu, Y. Shi, N. Meng, S. Lu, Y. Yu et al., Electrosynthesis of syngas via the co-reduction of $\mathrm{CO}_{2}$ and $\mathrm{H}_{2} \mathrm{O}$. Cell Rep. Phys. Sci. 1(11), 100237 (2020). https://doi.org/10.1016/j.xcrp.2020. 100237

5. Z.X. Tao, Z.S. Wu, Y.S. Wu, H.L. Wang, Activating copper for electrocatalytic $\mathrm{CO}_{2}$ reduction to formate via molecular interactions. ACS Catal. 10(16), 9271-9275 (2020). https:// doi.org/10.1021/acscatal.0c02237

6. Y. Xiong, J. Dong, Z.Q. Huang, P. Xin, W. Chen et al., Singleatom $\mathrm{Rh} / \mathrm{N}$-doped carbon electrocatalyst for formic acid oxidation. Nat. Nanotechnol. 15(5), 390-397 (2020). https://doi.org/ 10.1038/s41565-020-0665-x

7. S. Zhao, S. Li, T. Guo, S. Zhang, J. Wang et al., Advances in $\mathrm{Sn}$-based catalysts for electrochemical $\mathrm{CO}_{2}$ reduction. Nano Micro Lett. 11(1), 62 (2019). https://doi.org/10.1007/ s40820-019-0293-x
8. O.S. Bushuyev, P. De Luna, C.T. Dinh, L. Tao, G. Saur et al., What should we make with $\mathrm{CO}_{2}$ and how can we make it? Joule 2(5), 825-832 (2018). https://doi.org/10.1016/j.joule. 2017.09.003

9. J.M. Spurgeon, B. Kumar, A comparative technoeconomic analysis of pathways for commercial electrochemical $\mathrm{CO}_{2}$ reduction to liquid products. Energy Environ. Sci. 11(6), 1536-1551 (2018). https://doi.org/10.1039/c8ee00097b

10. N. Han, P. Ding, L. He, Y.Y. Li, Y.G. Li, Promises of main group metal-based nanostructured materials for electrochemical $\mathrm{CO}_{2}$ reduction to formate. Adv. Energy Mater. 10(11), (2020). Doi: https://doi.org/10.1002/aenm.201902338

11. P. Ding, H.T. Zhao, T.S. Li, Y.S. Luo, G.Y. Fan et al., Metalbased electrocatalytic conversion of $\mathrm{CO}_{2}$ to formic acid/formate. J. Mater. Chem. A 8(42), 21947-21960 (2020). https:// doi.org/10.1039/D0TA08393C

12. D. Wu, X.W. Wang, X.Z. Fu, J.L. Luo, Ultrasmall bi nanoparticles confined in carbon nanosheets as highly active and durable catalysts for $\mathrm{CO}_{2}$ electroreduction. Appl. Catal. B Environ. 284, 119723 (2021). https://doi.org/10.1016/j.apcatb. 2020.119723

13. Z.W. Seh, J. Kibsgaard, C.F. Dickens, I. Chorkendorff, J.K. Norskov et al., Combining theory and experiment in electrocatalysis: Insights into materials design. Science 355(6321), eaad4998 (2017). Doi: https://doi.org/10.1126/science.aad49 98

14. C.L. Xie, Z.Q. Niu, D. Kim, M.F. Li, P.D. Yang, Surface and interface control in nanoparticle catalysis. Chem. Rev. 120(2), 1184-1249 (2020). https://doi.org/10.1021/acs.chemrev.9b002 20

15. K. Chen, K. Qi, T. Zhou, T. Yang, Y. Zhang et al., Waterdispersible $\mathrm{CsPbBr}_{3}$ perovskite nanocrystals with ultra-stability and its application in electrochemical $\mathrm{CO} 2$ reduction. Nano-Micro Lett. 13(1), 172 (2021). https://doi.org/10.1007/ s40820-021-00690-8

16. Z. Pan, E. Han, J. Zheng, J. Lu, X. Wang et al., Highly efficient photoelectrocatalytic reduction of $\mathrm{CO}_{2}$ to methanol by a P-N heterojunction $\mathrm{CeO}_{2} / \mathrm{CuO} / \mathrm{Cu}$ catalyst. NanoMicro Lett. 12(1), 18 (2020). https://doi.org/10.1007/ s40820-019-0354-1

17. Y. Wu, P. Zhai, S. Cao, Z. Li, B. Zhang et al., Beyond d orbits: Steering the selectivity of electrochemical $\mathrm{CO}_{2}$ reduction via hybridized sp band of sulfur-incorporated porous cd architectures with dual collaborative sites. Adv. Energy Mater. 10(45), 2002499 (2020). https://doi.org/10.1002/aenm.202002499

18. B. Jiang, X.G. Zhang, K. Jiang, D.Y. Wu, W.B. Cai, Boosting formate production in electrocatalytic $\mathrm{CO}_{2}$ reduction over wide potential window on Pd surfaces. J. Am. Chem. Soc. 140(8), 2880-2889 (2018). https://doi.org/10.1021/jacs.7b125 06

19. H. Cheng, S. Liu, J. Zhang, T. Zhou, N. Zhang et al., Surface nitrogen-injection engineering for high formation rate of $\mathrm{CO}_{2}$ reduction to formate. Nano Lett. 20(8), 6097-6103 (2020). https://doi.org/10.1021/acs.nanolett.0c02144

20. X.L. Zheng, P. De Luna, F.P.G. de Arquer, B. Zhang, N. Becknell et al., Sulfur-modulated tin sites enable highly selective 
electrochemical reduction of $\mathrm{CO}_{2}$ to formate. Joule 1(4), 794805 (2017). https://doi.org/10.1016/j.joule.2017.09.014

21. Z.Z. Wu, F.Y. Gao, M.R. Gao, Regulating the oxidation state of nanomaterials for electrocatalytic $\mathrm{CO}_{2}$ reduction. Energy Environ. Sci. 14(3), 1121-1139 (2021). https://doi.org/10. 1039/d0ee02747b

22. D. Xue, H. Xia, W. Yan, J. Zhang, S. Mu, Defect engineering on carbon-based catalysts for electrocatalytic $\mathrm{CO}_{2}$ reduction. Nano-Micro Lett 13(1), 5 (2020). https://doi.org/10.1007/ s40820-020-00538-7

23. Y. Zhou, F. Che, M. Liu, C. Zou, Z. Liang et al., Dopantinduced electron localization drives $\mathrm{CO}_{2}$ reduction to $\mathrm{C}_{2}$ hydrocarbons. Nat. Chem. 10(9), 974-980 (2018). https://doi. org/10.1038/s41557-018-0092-x

24. S. Carenco, D. Portehault, C. Boissiere, N. Mezailles, C. Sanchez, Nanoscaled metal borides and phosphides: recent developments and perspectives. Chem. Rev. 113(10), 79818065 (2013). https://doi.org/10.1021/cr400020d

25. G. Kresse, J. Furthmuller, Efficiency of ab-initio total energy calculations for metals and semiconductors using a plane-wave basis set. Comput. Mater. Sci. 6(1), 15-50 (1996). https://doi. org/10.1016/0927-0256(96)00008-0

26. G. Kresse, J. Furthmuller, Efficient iterative schemes for ab initio total-energy calculations using a plane-wave basis set. Phys. Rev. B 54(16), 11169-11186 (1996). https://doi.org/ 10.1103/PhysRevB.54.11169

27. P.E. Blochl, Projector augmented-wave method. Phys. Rev. B 50(24), 17953-17979 (1994). https://doi.org/10.1103/PhysR evB.50.17953

28. G. Kresse, D. Joubert, From ultrasoft pseudopotentials to the projector augmented-wave method. Phys. Rev. B 59(3), 1758-1775 (1999). https://doi.org/10.1103/PhysRevB.59.1758

29. S. Grimme, J. Antony, S. Ehrlich, H. Krieg, A consistent and accurate $\mathrm{ab}$ initio parametrization of density functional dispersion correction (DFT-D) for the 94 elements H-Pu. J. Chem. Phys. 132(15), 154104 (2010). https://doi.org/10.1063/1. 3382344

30. K.X. Lei, C.C. Wang, L.J. Liu, Y.W. Luo, C.N. Mu et al., A porous network of bismuth used as the anode material for high-energy-density potassium-ion batteries. Angew. Chem. Int. Ed. 57(17), 4687-4691 (2018). https://doi.org/10.1002/ ange. 201801389

31. W. Hao, D. Yao, Q. Xu, R. Wang, C. Zhang et al., Highly efficient overall-water splitting enabled via grafting boroninserted $\mathrm{Fe}-\mathrm{Ni}$ solid solution nanosheets onto unconventional skeleton. Appl. Catal. B Environ. 292, 120188 (2021). https:// doi.org/10.1016/j.apcatb.2021.120188

32. Y. Li, H. Yu, Z. Wang, S. Liu, Y. Xu et al., Boron-doped silver nanosponges with enhanced performance towards electrocatalytic nitrogen reduction to ammonia. Chem. Commun. 55(98), 14745-14748 (2019). https://doi.org/10.1039/c9cc07232b

33. K. Khan, A.K. Tareen, M. Aslam, R.U.R. Sagar, B. Zhang et al., Recent progress, challenges, and prospects in twodimensional photo-catalyst materials and environmental remediation. Nano-Micro Lett. 12(1), 167 (2020). https://doi.org/ 10.1007/s40820-020-00504-3
34. G.R. Chen, J. An, Y.M. Meng, C.Z. Yuan, B. Matthews et al., Cation and anion co-doping synergy to improve structural stability of Li- and Mn-rich layered cathode materials for lithiumion batteries. Nano Energy 57, 157-165 (2019). https://doi. org/10.1016/j.nanoen.2018.12.049

35. K. Jiang, J. Chang, H. Wang, S. Brimaud, W. Xing et al., Small addition of boron in palladium catalyst, big improvement in fuel cell's performance: What may interfacial spectroelectrochemistry tell? ACS Appl. Mater. Interfaces 8(11), 7133-7138 (2016). https://doi.org/10.1021/acsami.6b00416

36. L. Zhang, J. Lu, S. Yin, L. Luo, S. Jing et al., One-pot synthesized boron-doped RhFe alloy with enhanced catalytic performance for hydrogen evolution reaction. Appl. Catal. B: Environ. 230, 58-64 (2018). https://doi.org/10.1016/j.apcatb. 2018.02.034

37. H. Lv, D. Xu, L. Sun, J. Henzie, S.L. Suib et al., Ternary palladium-boron-phosphorus alloy mesoporous nanospheres for highly efficient electrocatalysis. ACS Nano 13(10), 12052 12061 (2019). https://doi.org/10.1021/acsnano.9b06339

38. G. Zhang, Y. Xu, C. He, P. Zhang, H. Mi, Oxygen-doped crystalline carbon nitride with greatly extended visible-lightresponsive range for photocatalytic $\mathrm{H}_{2}$ generation. Appl. Catal. B: Environ. 283, 119636 (2021). https://doi.org/10.1016/j. apcatb.2020.119636

39. Y. Yang, L. Zhuang, R. Lin, M. Li, X. Xu et al., A facile method to synthesize boron-doped $\mathrm{Ni} / \mathrm{Fe}$ alloy nano-chains as electrocatalyst for water oxidation. J. Power Sources 349, 68-74 (2017). Doi: https://doi.org/10.1016/j.jpowsour.2017. 03.028

40. F. Wei, T. Wang, X. Jiang, Y. Ai, J. Cui et al., Controllably engineering mesoporous surface and dimensionality of $\mathrm{SnO}_{2}$ toward high-performance $\mathrm{CO}_{2}$ electroreduction. Adv. Funct. Mater. 30, 2002092 (2020). https://doi.org/10.1002/adfm. 202002092

41. D. Wu, J.W. Liu, Y. Liang, K. Xiang, X.Z. Fu et al., Electrochemical transformation of facet-controlled bioi into mesoporous bismuth nanosheets for selective electrocatalytic reduction of $\mathrm{CO}_{2}$ to formic acid. ChemSusChem 12(20), 4700-4707 (2019). https://doi.org/10.1002/cssc.201901724

42. M. Zhou, Y. Lin, H. Xia, X. Wei, Y. Yao et al., A molecular foaming and activation strategy to porous $\mathrm{N}$-doped carbon foams for supercapacitors and $\mathrm{CO}_{2}$ capture. Nano-Micro Lett. 12(1), 58 (2020). https://doi.org/10.1007/s40820-020-0389-3

43. X. Zhang, D. Kim, X. Guo, Y. Zhu, L.Y.S. Lee, Impacts of boron doping on the atomic structure, stability, and photocatalytic activity of $\mathrm{Cu}_{3} \mathrm{P}$ nanocrystals. Appl. Catal. B Environ. 298, 120515 (2021). https://doi.org/10.1016/j.apcatb. 2021. 120515

44. Y. Shi, Y. Ji, J. Long, Y. Liang, Y. Liu et al., Unveiling hydrocerussite as an electrochemically stable active phase for efficient carbon dioxide electroreduction to formate. Nat. Commun. 11(1), 3415 (2020). https://doi.org/10.1038/ s41467-020-17120-9

45. W. Zheng, F. Chen, Q. Zeng, Z. Li, B. Yang et al., A universal principle to accurately synthesize atomically 
dispersed metal- $\mathrm{N}_{4}$ sites for $\mathrm{CO}_{2}$ electroreduction. NanoMicro Lett. 12(1), 108 (2020). https://doi.org/10.1007/ s40820-020-00443-z

46. Y. Liang, W. Zhou, Y. Shi, C. Liu, B. Zhang, Unveiling in situ evolved $\mathrm{In} / \mathrm{In}_{2} \mathrm{O}_{3}$ heterostructure as the active phase of $\mathrm{In}_{2} \mathrm{O}_{3}$ toward efficient electroreduction of $\mathrm{CO}_{2}$ to formate. Sci. Bullet. 65(18), 1547-1554 (2020). https://doi.org/10.1016/j.scib. 2020.04 .022

47. N. Meng, W. Zhou, Y. Yu, Y. Liu, B. Zhang, Superficial hydroxyl and amino groups synergistically active polymeric carbon nitride for $\mathrm{CO}_{2}$ electroreduction. ACS Catal. 9(12), 10983-10989 (2019). https://doi.org/10.1021/acscatal.9b038 95

48. M. Dunwell, W. Luc, Y.S. Yan, F. Jiao, B.J. Xu, Understanding surface-mediated electrochemical reactions: $\mathrm{CO}_{2}$ reduction and beyond. ACS Catal. 8(9), 8121-8129 (2018). https://doi. org/10.1021/acscatal.8b02181

49. X.L. Zhang, X.H. Sun, S.X. Guo, A.M. Bond, J. Zhang, Formation of lattice-dislocated bismuth nanowires on copper foam for enhanced electrocatalytic $\mathrm{CO}_{2}$ reduction at low overpotential. Energy Environ. Sci. 12(4), 1334-1340 (2019). https://doi.org/10.1039/C9EE00018F

50. D. Wu, G. Huo, W.Y. Chen, X.Z. Fu, J.L. Luo, Boosting formate production at high current density from $\mathrm{CO}_{2}$ electroreduction on defect-rich hierarchical mesoporous $\mathrm{Bi} / \mathrm{Bi}_{2} \mathrm{O}_{3}$ junction nanosheets. Appl. Catal. B: Environ. 271, 118957 (2020). https://doi.org/10.1016/j.apcatb.2020.118957

51. P. Deng, H. Wang, R. Qi, J. Zhu, S. Chen et al., Bismuth oxides with enhanced bismuth-oxygen structure for efficient electrochemical reduction of carbon dioxide to formate. ACS Catal. 10(1), 743-750 (2020). https://doi.org/10.1021/acsca tal.9b04043

52. A.M. Ismail, G.F. Samu, A. Balog, E. Csapo, C. Janaky, Composition-dependent electrocatalytic behavior of Au-Sn bimetallic nanoparticles in carbon dioxide reduction. ACS Energy Lett. 4(1), 48-53 (2019). https://doi.org/10.1021/acsenergyl ett. 8 b01996

53. A. Vasileff, X. Zhi, C.C. Xu, L. Ge, Y. Jiao et al., Selectivity control for electrochemical $\mathrm{CO}_{2}$ reduction by charge redistribution on the surface of copper alloys. ACS Catal. 9(10), 9411-9417 (2019). https://doi.org/10.1021/acscatal.9b02312

54. W.T. Ichinohe Y, Hatta A, Electrochemical reduction of $\mathrm{CO}_{2}$ on silver as probed by surface-enhanced raman scattering. J.
Raman Spectrosc. 26(5), 335-340 (1995). Doi: https://doi.org/ 10.1002/jrs. 1250260503

55. L. Jiao, W.J. Yang, G. Wan, R. Zhang, X.S. Zheng et al., Single-atom electrocatalysts from multivariate metal-organic frameworks for highly selective reduction of $\mathrm{CO}_{2}$ at low pressures. Angew. Chem. Int. Ed. 59(46), 20589-20595 (2020). https://doi.org/10.1002/ange.202008787

56. E.H. Zhang, T. Wang, K. Yu, J. Liu, W.X. Chen et al., Bismuth single atoms resulting from transformation of metal-organic frameworks and their use as electrocatalysts for $\mathrm{CO}_{2}$ reduction. J. Am. Chem. Soc. 141(42), 16569-16573 (2019). https://doi. org/10.1021/jacs.9b08259

57. Z.P. Chen, K.W. Mou, X.H. Wang, L.C. Liu, Nitrogendoped graphene quantum dots enhance the activity of $\mathrm{Bi}_{2} \mathrm{O}_{3}$ nanosheets for electrochemical reduction of $\mathrm{CO}_{2}$ in a wide negative potential region. Angew. Chem. Int. Ed. 57(39), 12790-12794 (2018). https://doi.org/10.1002/ange.201807643

58. W.C. Ma, S.J. Xie, X.G. Zhang, F.F. Sun, J.C. Kang et al., Promoting electrocatalytic $\mathrm{CO}_{2}$ reduction to formate via sulfurboosting water activation on indium surfaces. Nat. Commun. 10, 892 (2019). https://doi.org/10.1038/s41467-019-08805-x

59. N.T. Nesbitt, T. Burdyny, H. Simonson, D. Salvatore, D. Bohra et al., Liquid-solid boundaries dominate activity of $\mathrm{CO}_{2}$ reduction on gas-diffusion electrodes. ACS Catal. 10, 14093-114106 (2020). https://doi.org/10.1021/acscatal.0c03319

60. H. Ooka, M.C. Figueiredo, M.T.M. Koper, Competition between hydrogen evolution and carbon dioxide reduction on copper electrodes in mildly acidic media. Langmuir 33(37), 9307-9313 (2017). https://doi.org/10.1021/acs.langmuir. $7 b 00696$

61. T.Y. Liu, P. Diao, Z. Lin, H.L. Wang, Sulfur and selenium doped nickel chalcogenides as efficient and stable electrocatalysts for hydrogen evolution reaction: The importance of the dopant atoms in and beneath the surface. Nano Energy 74, 104787 (2020). https://doi.org/10.1016/j.nanoen.2020.104787

62. Z.P. Chen, X.X. Zhang, M.Y. Jiao, K.W. Mou, X.P. Zhang et al., Engineering electronic structure of stannous sulfide by amino-functionalized carbon: Toward efficient electrocatalytic reduction of $\mathrm{CO}_{2}$ to formate. Adv. Energy Mater. 10(8), 1903664 (2020). https://doi.org/10.1002/aenm.201903664 